\title{
Neurolinguistic Research on the Romance Languages
}

Valentina Bambini, Paolo Canal

\section{Summary}

Neurolinguistics is devoted to the study of the language-brain relationship, using the methodologies of neuropsychology and cognitive neuroscience to investigate how linguistic categories are grounded in the brain. Although the brain infrastructure for language is invariable across cultures, neural networks might operate differently depending on language-specific features. In this respect, neurolinguistic research on the Romance languages, mostly French, Italian, and Spanish, proved key to progress the field, especially with specific reference to how the neural infrastructure for language works in the case of more richly inflected systems than English.

Among the most popular domains of investigation are agreement patterns, where studies on Spanish and Italian showed that agreement across features and domains (e.g., number or gender agreement) engages partially different neural substrates. Also, studies measuring the electrophysiological response suggested that agreement processing is a composite mechanism involving different temporal steps. Another domain is the noun-verb distinction, where studies on the Romance languages indicated that the brain is more sensitive to the greater morphosyntactic engagement of verbs compared with nouns rather than to the grammatical class distinction per se.

Concerning language disorders, the Romance languages shed new light on inflectional errors in aphasic speakers and contributed to revise the notion of agrammatism, which is not simply omission of morphemes but might involve incorrect substitution from the inflectional paradigm. Also, research in the Romance domain showed variation in degree and pattern of reading impairments due to language-specific segmental and suprasegmental features.

Despite these important contributions, the Romance family, with its multitude of languages and dialects and a richly documented diachronic evolution, is a still under-utilized 'treasure house' for 
neurolinguistic research, with large room for investigations exploring the brain signatures of language variation in time and space, and for refining the linking between linguistic categories and neurobiological primitives.

\section{Keywords}

agreement; noun-verb distinction; agrammatism; neurolinguistics; Romance languages 


\section{Defining Romance Neurolinguistics}

Neurolinguistics investigates the language-brain relationship, encompassing a variety of aspects, from comprehension to production, from acquisition to decay, in pathological and healthy conditions (Bambini, 2012). Different perspectives might be adopted for studying the relationship between language and the brain. In the fields known as cognitive neuroscience of language and neurobiology of language, the main concern is how the brain mechanisms and neurocomputational constraints make language emerge (Small et al., 2011); conversely, neurolinguistics is more interested in what and how linguistic categories are supported, indeed grounded, in the brain (Obler \& Gjerlow, 1999). Neurolinguistics is thus largely tied to theoretical linguistics for defining the relevant categories to investigate and for informing language models.

Needless to say, since the neural devices for language processing are shared across cultures and represent a biological endowment of the human species, restricting the scope of a review to one language family may only mean that one is to address the neurolinguistic research that has been conducted on (the speakers of) the languages at issue as empirical object. In this perspective, one can exploit the contrasting typological features of the different languages to investigate the relevance for the brain of specific grammatical features, also in comparison with analogous features in other language families. Romance neurolinguistics should thus be intended as the neurolinguistic research conducted on speakers of the Romance family, broadly defined as those languages and dialects that share Latin as ancestor (for a comprehensive overview of the Romance family, see article n.1 in this Encyclopedia "The Romance Language family"; see also Bossong, 2016). Indeed, the last decades have witnessed a growing interest in the brain correlates of some Romance languages, especially Spanish, French, and Italian. These languages, with their specific characteristics such as for instance a richer morphological system compared with English, proved key to advance our understanding of how linguistic processes are supported by the brain.

This chapter is organized as follows: After providing a brief overview of the main methodologies adopted in neurolinguistics (section 2) and the state of the art concerning the general brain architecture 
for language (section 3), it will focus on three specific thematic domains, namely grammatical agreement patterns (section 4), the noun-verb distinction (section 5), and some aspects of language disorders (section 6). These three domains differ for the methodologies used and the populations tested, yet they were chosen here because in these domains, the research that specifically targeted the Romance languages provided crucial evidence for advancing our understanding of the neural correlates of language. They are thus highly relevant for Romance neurolinguistics. With this aim in mind, the chapter reviews studies on different populations and investigating different grammatical features in different modalities, which will be in turn specified in each section.

\section{Methods}

Neurolinguistic research makes use of the whole range of tools available in neuroscience. Historically, the first discipline describing the brain mechanisms mediating language comprehension and production was neuropsychology, that is, the study of how behavior and cognition change after structural damage (McCarthy \& Warrington, 1990). Studies on clinical populations still represent an important source of evidence, yet they are complemented by other techniques that provide the opportunity to study healthy brain functioning. Neural cells communicate through electro-chemical signals and to do so they use metabolic resources: While language users read or listen to words or sentences, the electrical and metabolic correlates of neural activity can be measured. Such measurements represent the variables of interest of the two main families of techniques, based on electrophysiological and metabolic response respectively. Techniques are also characterized in terms of spatial resolution (i.e., the ability of detecting where a change in neural activity occurred) and temporal resolution (i.e., the ability of detecting when a change in neural activity occurred), as illustrated in Figure 1 (see also Sejnowski, Churchland, \& Movshon, 2014). ${ }^{i}$ In some cases, different techniques measure the correlates of the very same neural activity generated in the cortex of the brain but focusing on different aspects and can thus be considered complementary. For instance, both EEG and MEG are sensitive to the electrical currents generated by populations of pyramid cells, but the 
magnetic fields measured by MEG are generated by currents that run tangential to the scalp, while voltage changes measured by the EEG are detected when currents are perpendicular to the scalp.

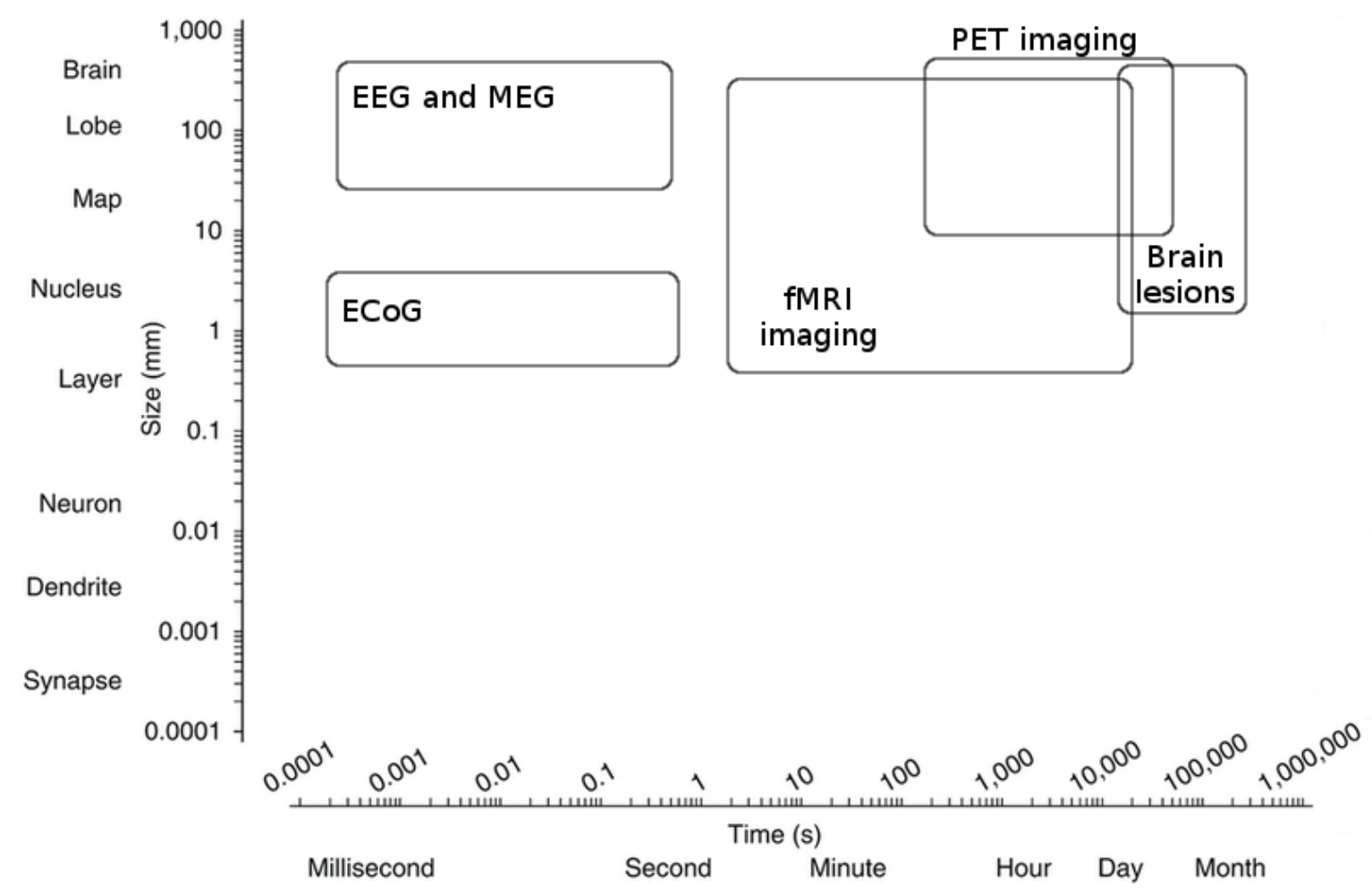

Figure 1: The spatiotemporal domain of the main neuroscientific methods used in neurolinguistic research.

Each region represents the domain of spatial and temporal resolution for each method. The areas depicted for each domain are somewhat arbitrary and represent estimates. Adapted from Sejnowski, Churchland, \& Movshon (2014).

With the exception of neuropsychology, in which also single case studies are relevant, neuroscientific methods use averaging in order to reach a sufficient ratio between signal of interest and the noise/error that is necessarily associated with each technique. Results represent the average response of participants sampled from a population of interest, to a sample of stimuli organized along different experimental conditions. It is also relevant to point out that research conducted on language comprehension and production mostly focused on right handed participants, to avoid confusion that 
could derive from mixing results from participants with left and right-hemisphere language dominance (Knecht et al., 2000).

Because each technique has its own strengths and weaknesses, a choice about which methodology is the most appropriate to test the research question at stake has to be made, to begin with. Furthermore, a variety of experimental paradigms exist to investigate the different aspects of language processing: Lexical semantic processes are typically studied by means of lexical decision or priming tasks; syntactic mechanisms are investigated using grammatical violations or manipulating syntactic complexity; phonological processes are often studied using mismatch paradigms, for instance to test whether people perceive different phonological properties of standard and deviant sounds.

\subsection{Measures Derived from Electrophysiological Activity}

The electrical signal generated in the brain cortex by populations of neurons travels with zero latency within the brain. The electrical activity of the brain is perturbated by the cognitive events associated with the processing of experimental stimuli: When changes concern amplitude measures they are referred to as "event-related", while when they concern frequency measures they are said to be "induced". To capture event-related or induced changes in electrophysiological activity we can measure voltage changes from the scalp with the EEG, or magnetic fields using the MEG. The excellent temporal resolution of this family of techniques is due to the fast transmission of electric currents within the brain.

\subsubsection{Electroencephalography (EEG)}

With the EEG technique the electrical activity of the brain is measured from the scalp (with low health risks), using a set of electrodes (Luck \& Kappenman, 2012). The measurement of the EEG has a long history, and it is today used to investigate the electrical activity that is associated with an experimental event focusing on Event-Related Potentials (ERP) or on Time Frequency Representations (TFR). Researchers have isolated a set of ERP components, that is, the neural activity generated in a brain 
'module' responsible for a specific stage of processing. Components are described in terms of polarity (P-positive and N-negative), latency of the peak (in ms) and typical scalp distribution. For instance, the N400 component is a negative deflection of ERPs with a peak around $400 \mathrm{~ms}$ in central parietal electrodes that has since more than 30 years been taken to reflect lexical semantic processing of the word as influenced by the previous context (Kutas \& Federmeier, 2011). Measures based on the EEG have excellent temporal resolution yet poor spatial resolution, but this approach is noninvasive and by far more economic as compared with other techniques such as electrocorticography and magnetoencephalography.

\subsubsection{Electrocorticography $(E C o G)$}

With ECoG the cortical activity is recorded placing a set of electrodes directly in contact with the exposed brain after cranioctomy in the operating room (Ritaccio et al., 2015). Compared with the EEG, ECoG allows for the detection of more subtle voltage differences and for a better spatial definition, because the signal does not undergo dispersion and attenuation due to the skull resistance. However, the clinical context in which ECoG research is carried out naturally imposes several limitations, including where and for how long the electrodes can be placed, which are factors depending on the patient's clinical condition. Nonetheless, this technique offers a unique window of analysis on the brain function and may play an important role in further developments of BrainComputer interface.

\subsubsection{Magnetoencephalography (MEG)}

The MEG technique measures the magnetic fields induced by the flow of cortical and to some extent subcortical currents generated in the brain (Hansen, Kringelbach, \& Salmelin, 2010). Being the magnitude of these fields smaller than the environmental magnetic noise, this technique needs an environment with strong magnetic shielding. The signal is captured by a large array of sensors (typically 300 superconducting quantum interference devices, SQUIDs) and although the 
neurophysiological process generating it is the same of that generating the EEG signal, the MEG is sensitive to currents that flow with a different orientation, and allows for a better approximation of the localization of the neural sources. Moreover, MEG can be combined with structural data to gain optimal spatial resolution.

\subsection{In Vivo Representations of the Human Brain's Anatomy}

The study of in vivo brain anatomy has greatly developed thanks to Magnetic Resonance Imaging (MRI) technique, which is based on the principles of nuclear magnetic resonance: Using radio waves, magnetic fields and field gradients, MRI can scan a body volume and locate water and fat in the volume (Huettel, Song, \& McCharthy, 2008). MRI machines capture static pictures of the brain structure, and with the development of diffusion tensor imaging (DTI; Basser, Mattiello, \& LeBihan, 1994), the MRI can also visualize the pathways of white matter of the living brain, revealing the connectivity of different brain areas (Catani \& Mesulam, 2008).

\subsection{Measures derived from metabolic activity}

The generation of electro-chemical signals by populations of neurons has metabolic costs. When neurons in a brain region are "firing", the energetic demands in that region increase. Functional neuroimaging techniques monitor how different areas request consumption of different metabolites or blood oxygen (Blood-oxygen-level dependent contrast imaging - BOLD signal), and do so with an excellent spatial resolution. Positron emission Tomography (PET) is used to monitor metabolic processes in the body by detecting gamma rays emitted by a radionuclide injected in the patient that can be used as tracer to reveal the pathway of several substances (e.g., neurotransmitters, drug molecules) in the living body. Instead, by measuring the BOLD signal, functional Magnetic Resonance Imaging (fMRI) can provide information about the consumption of oxygen in different cortical and subcortical regions of the brain as it unfolds in time. Because the BOLD response is not 
as rapid as the electrical activity generated by neural cells, the temporal resolution of fMRI is relatively poor compared with the excellent spatial resolution (Logothetis, 2008).

\section{Levels of Linguistic Representation and Neurobiological Models of Language}

The empirical evidence available today indicates that the network of brain areas responsible for language processing is a complex slightly left dominant bilateral network, which involves both posterior and anterior portions of the middle and superior temporal gyri, the left inferior frontal gyrus, and the left premotor cortex (Hickok \& Poeppel, 2007). Within the left inferior frontal gyrus, different portions are involved in language, including pars opercularis and triangularis (Brodmann Areas 44 and 45, respectively, forming the so-called Broca's area), and pars orbitalis (Brodmann Area 47) (Amunts et al., 2010).

These regions are differently involved in the different levels of linguistic representations, from sound to meaning, as revealed by a large body of evidence of brain imaging studies (mostly PET, fMRI and lately MEG) conducted mainly on healthy individuals in the last 20 years. Phonological processing, as part of auditory speech perception, is supported by a neural system located in the superior temporal lobe, involving especially the superior temporal sulcus, bilaterally (Hickok \& Poeppel, 2007). Its activation is observed both in studies comparing speech stimuli with non-speech signals and in investigations that tap phonological processing systems (Hickok, 2009). At the phonetic level, distinct features seem to be represented along the superior temporal gyrus (Mesgarani, Cheung, Johnson, \& Chang, 2014). Research on morphology has mainly focused on the contrast between regular vs. irregular forms. According to the Declarative/Procedural model, regular forms are supported by a rule-governed system rooted in frontal cortical regions, including Broca's area, and basal ganglia, whereas irregular forms are supported by lexical processes rooted in the temporal lobe (Ullman, 2001). Syntactic processing has been investigated through a variety of paradigms, including selective

rules violation (Embick, Marantz, Miyashita, O’Neil, \& Sakai, 2000; Moro et al., 2001) or 
manipulation of the complexity of sentence structures (Pallier, Devauchelle, \& Dehaene, 2011). Overall, results point to the crucial role of Broca's area in syntactic computation, often extending to posterior temporal regions in sentential analysis tasks such as the detection of syntactic ambiguity (Tyler \& Marslen-Wilson, 2008). The system for the storing of semantic information appears extremely distributed (Binder, Desai, Graves, \& Conant, 2009; Cappa, 2012). The prominent Hub and Spoke Model assumes that semantic representations are formed by extracting modality-specific information (e.g., perceptual properties such as shape and color), which are integrated at the conceptual level in an amodal fashion (i.e., independently of the specific modality) in the anterior temporal pole hub (Lambon Ralph, Jefferies, Patterson, \& Rogers, 2016; Patterson, Nestor, \& Rogers, 2007). Recent studies on figurative language and discourse processes (Bambini, Gentili, Ricciardi, Bertinetto, \& Pietrini, 2011; Spotorno, Koun, Prado, Van Der Henst, \& Noveck, 2012; Zacks \& Ferstl, 2016) revealed the brain networks engaged in pragmatic integration, pointing to the involvement of fronto-temporo-parietal connections, with a special role of the temporo-parietal junction in inferring the speaker's meaning (Hagoort \& Levinson, 2014).

One of the most outstanding achievements of research in the last decade is the description of how the different language hubs are connected to each other (using fMRI and capitalizing on the development of DTI measures). Connections between areas run through complex white matter pathways, among which the main ones are known as the dorsal and ventral streams. In analogy to the visual system (Goodale \& Milner, 1992), the ventral stream (involving structures in the superior and middle portions of the temporal lobe) can be broadly construed as an auditory "what" system that processes speech signals for comprehension, mapping the sound structures of words onto the corresponding semantic representations and contributing to form the integrated meanings of phrases and sentences; conversely, the dorsal pathway (encompassing posterior frontal and parietal temporal regions) can be considered as an integrated interface in which speech signals are translated in articulatory representations (Hickok, 2012; Hickok \& Poeppel, 2007). Other scholars emphasize the role of the dorsal route in grammatical processing (Friederici \& Gierhan, 2013) or the importance, in addition to 
the dorsal and ventral route, of other pathways responsible for communicative and pragmatic aspects (Catani \& Bambini, 2014).

Overall, the combined effort of neurolinguistic research across languages, not only Romance, allowed to reach a quite detailed description of the brain areas involved in language at different levels of the linguistic analysis, which represents the actual state of the art.

\section{Grammatical Agreement Patterns}

One of the most important processing mechanisms that help the brain in building a coherent sentence representation is agreement. In Romance languages, and more generally in richly inflected languages, many sentence constituents co-vary according to other sentence constituents, and those processes responsible for checking and binding co-varying constituents are crucial for comprehension. Adopting Corbett's terminology (Corbett, 2006), the controller of the agreement process is the element that determines the agreement (e.g., a noun) while the element whose form changes as a function of the controller's features is the target (e.g., a determiner). Agreement for a given linguistic feature (e.g., person, animacy, gender, number) may occur in different domains (e.g., noun phrase and verb phrase). Several studies on Romance languages studied agreement processes, using the full range of methodologies available for neurolinguistic research. The next two sub-sections consider studies employing the fMRI methodology (4.1) and the ERP technique (4.2).

\subsection{Functional Neuroimaging Studies on Agreement}

A large number of fMRI studies on healthy individuals investigated where in the brain the processing of a particular agreement feature occurs, mostly by using written stimuli and a variety of paradigms. Here studies on the processing of different agreement features in isolation and in morphosyntactic agreement contexts (phrases or sentences) will be briefly surveyed. To begin with, Miceli and colleagues presented participants with Italian nouns and found that, when subjects were required to make grammatical decisions on the nouns' gender, activations in Broca's area increased (Miceli et 
al., 2002). In another study, Spanish nouns were used to compare the processing of grammatical gender-transparent words such as carro 'car', which have canonical endings ( $-a$ for feminine and $-o$ for masculine), with the processing of opaque nouns like arroz 'rice' where no cues to grammatical gender are provided by the noun ending (Hernandez et al., 2004). The processing of opaque words brought to increased activation of the left inferior frontal gyrus, and similar patterns were reported for Italian (Padovani, Calandra-Buonaura, Cacciari, Benuzzi, \& Nichelli, 2005).

Also agreement operations, involving checking and matching target and controller features, are carried out in Broca's area (Indefrey, Hagoort, Herzog, Seitz, \& Brown, 2001). However, as we noted earlier, agreement occurs for several distinct features, so the question became whether the computation of agreement of distinct features is carried out with one and the same mechanism. To this aim richly inflected languages represent the ideal test bed because they display an array of linguistic features that can be compared to each other. Carreiras and colleagues (Carreiras, Carr, Barber, \& Hernandez, 2010) used fMRI to test differences in processing gender and number features, using written word pairs (determiner-noun and noun-adjective) that could agree in number and gender (el piano, the $\mathrm{M}_{\mathrm{SG}}$ piano $\mathrm{M}_{\mathrm{SG}}$ ) or disagree in gender (la piano, the $\mathrm{F}_{\mathrm{FG}}$ piano $\mathrm{M}_{\mathrm{SG}}$ ) or number (faro altos, lighthouse $_{M . S G}$ high $_{M . P L}$ ). Authors showed that agreement violations increased activation of left premotor and inferior frontal areas. Crucially however, compared with gender agreement violations, number agreement elicited a broader pattern of activation including the right intraparietal sulcus, a region involved in the computation of quantity. This evidence suggests that processing agreement of different features may involve distinct brain circuitry.

Along these lines also the comparison of agreement processes across different syntactic domains produced interesting findings. Using written stimuli, another work on Spanish compared number agreement in nominal $\left(e l / * l o s\right.$ anillo, the $\mathrm{M}_{\mathrm{MG}} /$ the $_{\mathrm{M} . \mathrm{PL}}$ ring $\left._{\mathrm{MSG}}\right)$ and subject-verb (Ella/*Ellas baila, she $_{\text {F.SG/theyF.PL dances }}$ SSG $_{3}$ ) domains (Carreiras, Quiñones, Mancini, Hernández-Cabrera, \& Barber, 2015). Common patterns of activations involving the so-called conflict monitoring system were observed for violations in both nominal and subject-verb contexts. But the most important finding 
concerned the activation pattern in the anterior portion of the temporal lobe, where differences between domains emerged. In the verbal domain, this region was equally active in both match and mismatch condition, whereas in the nominal domain, the mismatch determined a decrease of activation. These results suggest that in the verbal domain agreement relations are computed regardless of the mismatch, whereas in the nominal domain the computation of agreement is blocked by the mismatch. Another work (Mancini, Quiñones, Molinaro, Hernandez-Cabrera, \& Carreiras, 2017) investigated the violation of different features (person and number) in subject-verb agreement: a quantitative difference between person and number violations emerged in the posterior portion of the middle temporal gyrus (with person inducing larger activation than number), while a qualitative difference between the features emerged in the anterior portion of the middle temporal gyrus, where only person violations elicited a significant increase of activation.

\subsection{Electrophysiological Studies on Agreement}

Most research devoted to testing differences across features and domains of agreement in the Romance languages used electrophysiological methods. The largest body of evidence on agreement mechanisms comes from research using ERPs, most often assessing morphosyntactic agreement during written phrase or sentence comprehension in healthy individuals (Molinaro, Barber, \& Carreiras, 2011). Studies investigated Romance languages such as Spanish (Barber \& Carreiras, 2005; Caffarra \& Barber, 2015; Caffarra, Janssen, \& Barber, 2014; Caffarra, Mendoza, \& Davidson, 2019), Italian (Angrilli et al., 2002; Caffarra, Siyanova-Chanturia, Pesciarelli, Vespignani, \& Cacciari, 2015; De Vincenzi et al., 2003; Molinaro, Vespignani, \& Job, 2008; Molinaro, Vespignani, Zamparelli, \& Job, 2011), and French (Frenck-Mestre, Osterhout, McLaughlin, \& Foucart, 2008). This body of evidence capitalized on the different roles of the two components that are associated with the processing of agreement violations. Agreement violations: (a) elicit larger Left Anterior Negativity (LAN), occurring between 300 and $450 \mathrm{~ms}$ and (b) modulate the P600 component, occurring between 500 and $900 \mathrm{~ms}$. Each component is assumed to have a specific role in agreement processing. The 
LAN represents an early stage of error detection and is most likely associated with automatic morphosyntactic processing, whereas the P600 represents a later stage of reanalysis or repair of incorrect agreement relations (Figure 2). ${ }^{\text {ii }}$

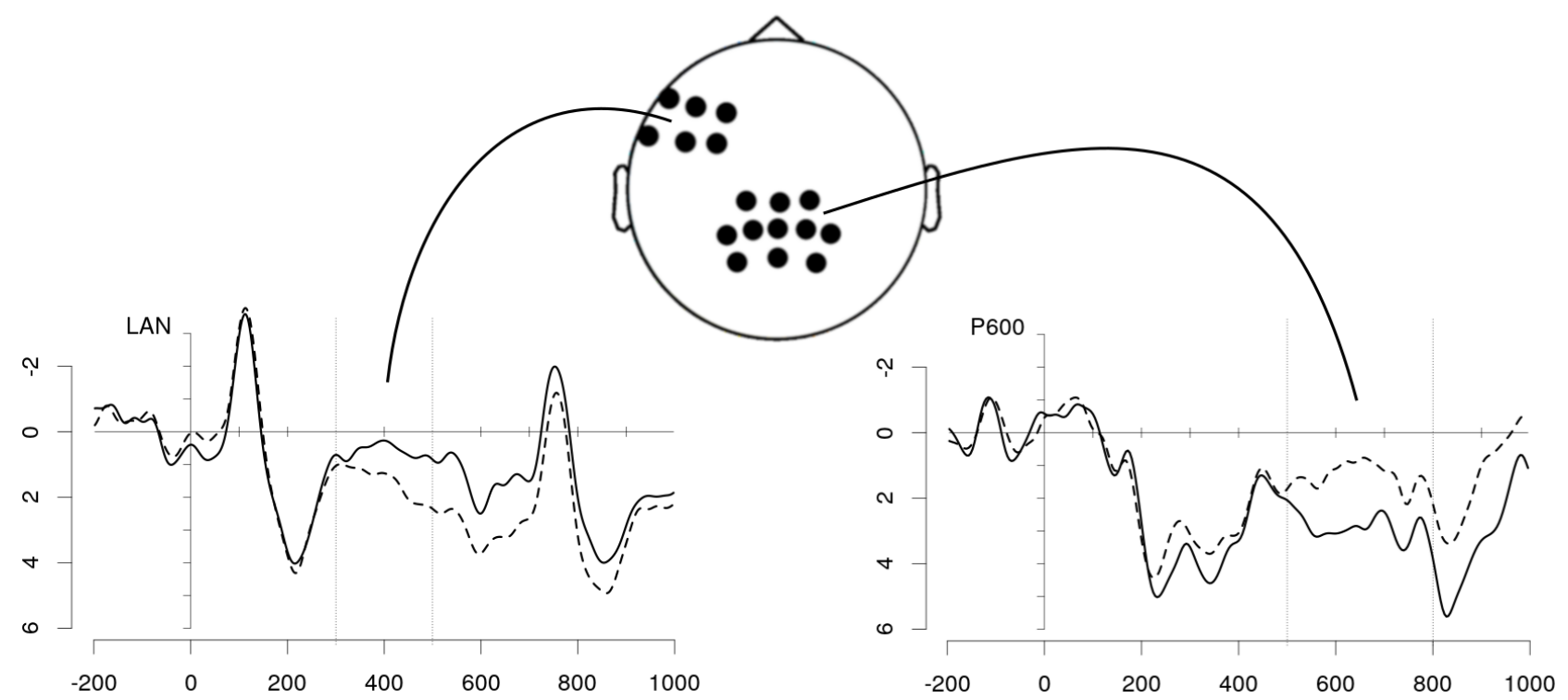

Figure 2: LAN and P600 effects.

The figure depicts the ERPs for two hypothetical conditions, for instance match condition (dotted line) and mismatch condition (solid line). The two panels refer to different scalp locations (specified by the dots in the head model), where LAN effects (on the left) and P600 effects (on the right) are most likely to occur. The y-axis represents voltage, with negativity plotted down. The x-axis represents time. Vertical markers indicate the typical time-windows of the effects. Source: Author.

A few studies directly compared the processing of distinct features or different domains. For instance, Mancini and colleagues used ERPs to show that number and person violations in the subject-verb domain in Spanish are differently processed, with number violations being associated with LAN and P600 effects, and person violations eliciting N400 and P600 effects (Mancini, Molinaro, Rizzi, \& Carreiras, 2011). Since the N400 reflects lexical-semantic and contextual operations, these results 
suggest that person violations induce more interpretive problems, compared with number violations. Along a similar line, Molinaro and colleagues compared the MEG correlates of number and gender (dis)agreement processes in Spanish, in the noun phrase domain and employing sentences (Molinaro, Barber, Pérez, Parkkonen, \& Carreiras, 2013). Only number violations elicited an early effect (170$180 \mathrm{~ms}$ ) in left occipital-temporal regions, typically involved in morphological decomposition. Instead, both violations elicited similar effects in two later time windows: around $250 \mathrm{~ms}$ in the anterior portion of the temporal lobe, where basic combinatorial operations take place, and soon after $300 \mathrm{~ms}$ in brain regions close to the pars opercularis, consistently with the view that BA44 may be involved in more controlled syntactic processing.

Finally, other non-morphosyntactic forms of agreement have been investigated. For instance, in coreferential expressions antecedent and anaphor must agree in number and gender to allow for identifying two different parts of the discourse as referring to the same discourse entity. In this domain, given the involvement of information structure and discourse related aspects, the range of ERP components is expanded to the N400 and the so-called Nref, a sustained negativity for ambiguous reference (Van Berkum, Koornneef, Otten, \& Nieuwland, 2007). Whereas the processing of anaphoric relations has received considerable attention in English, Dutch, and German (Callahan, 2008), only limited evidence comes from Romance languages, mainly Italian (Domaneschi, Canal, Masia, Lombardi Vallauri, \& Bambini, 2018; Masia, Canal, Ricci, Lombardi Vallauri, \& Bambini, 2017). Another topic that would deserve more attention in relation to Romance languages is the study of clitics and other reduced pronominal forms, up to now confined mainly to investigations in the context of bilingualism (German, Herschensohn, \& Frenck-Mestre, 2015; Rossi, Kroll, \& Dussias, 2014).

To summarize the content of this section, the study of agreement is a good example of how research on Romance languages contributed to a better understanding of the brain mechanisms that serve comprehension. FMRI studies showed that different morphological features are associated with nonoverlapping brain networks and might thus be represented differently. When research focused on the 
temporal development of the agreement process, ERP measures indicate that agreement process is a composite mechanism dealing with different kinds of information and unfolding through different steps.

\section{The Noun-Verb Distinction}

The noun-verb distinction is a landmark of grammatical description. All languages exhibit different behavior (syntactic and morphosyntactic) for classes of words that fit into nouns and verbs. Therefore this distinction is a good candidate for being part of the neurobiological system hosting the language faculty, and indeed it has been the focus of a large deal of literature (Crepaldi, Berlingeri, Paulesu, \& Luzzatti, 2011; Kemmerer, 2014; Vigliocco, Vinson, Druks, Barber, \& Cappa, 2011). At the same time, the degree to which languages exhibit a noun-verb distinction varies, making this domain apt to test typological differences and possibly specific patterns associated with the Romance languages. This section reviews findings coming mainly from neuropsychological studies on clinical populations and from neuroimaging studies, mostly with oral production tasks.

Evidence of a noun vs. verb separation in the brain has been documented for centuries through the tales of clinical cases of selective impairment following acquired brain lesion, starting from the passage by the Italian philosopher Giambattista Vico in the Principles of New Science published in 1744 ("Amongst us lives an honest man, touched by a very grave apoplexy, who spoke nouns and wholly forgot verbs"; cited in Denes, 2011) to the examination reports of soldiers with head injuries in World War I whose speech was reduced to nouns and lacked verbs (Dal Maso, 2015). Selective impairments started to be investigated scientifically in the 1980 s, collecting a large evidence of data from spontaneous speech as well as other tasks, including picture description, oral and written picture naming, and word-to-picture matching. Focusing on naming, between 1984 and 2006, 240 cases of patients with focal lesions with a relative impairment of nouns or verb in naming task were documented in 38 papers (Mätzig, Druks, Masterson, \& Vigliocco, 2009). Of these papers, almost 1/3 concerned aphasic Italian speakers (while the rest involved speakers of Germanic languages). 
Overall, although deficits in verbs were more frequent, some studies reported selective impairments in nouns too, hence pointing to a double dissociation indicative of separate representations of nouns and verbs.

A seminal study by Damasio and Tranel (Damasio \& Tranel, 1993) laid down the basis for the idea of a neuroanatomical separation of the noun-verb distinction, the so-called "fronto-temporal dichotomy hypothesis" (Crepaldi et al., 2011). The authors reported three cases of English speaking patients with almost pure naming deficit: Patients Boswell and AN-1033 performed poorly when asked to name nouns from pictures (for instance, by producing the superordinate category, e.g., bird for $d u c k$ ) while being virtually perfect with verbs; patient KJ-1360 was impaired with verbs (e.g., going... scissoring for cutting) but unimpaired with nouns. The double dissociation was accompanied by different lesion sites. Whereas the patients impaired with nouns had lesion affecting the temporal lobe (shared in left anterior and middle temporal lobe), the patients impaired with verbs had lesions located in the posterior segment of the left inferior frontal gyrus and the anterior segment of the left precentral gyrus. Soon after the publication of these data, similar findings were reported for three Italian brain-damaged patients (Daniele, Giustolisi, Silveri, Colosimo, \& Gainotti, 1994), and the literature on the topic continues to be very lively (Benetello et al., 2016).

Other studies proved that not only focal lesions but also neurodegenerative diseases might lead to selective noun vs. verb impairment. Cappa and colleagues contrasted Italian patients with Alzheimer's disease, centered on the temporal lobe, and patients with frontotemporal dementia, mainly affecting the frontal lobe and the anterior portion of the temporal lobe (Cappa et al., 1998). The latter group of patients performed more poorly than the former group in the action naming compared with the object naming task. A further study on Italian showed that not all frontotemporal dementia patients are alike: The worst performance on verbs was obtained by non-fluent agrammatic patients, as opposed to those affected by other variants of frontotemporal dementia, as well as by patients with other conditions characterized by prominent movement disorders (Cotelli et al., 2006). However, the picture is not straightforwardly in support of the fronto-temporal dichotomy hypothesis. 
First, authors argued that the reported findings might mix grammatical and semantic effects (Vigliocco et al., 2011), as the tasks, especially naming tasks, confounded the grammatical distinction between noun and verbs and the semantic/conceptual level. Second, the application of neuroimaging methodology did not confirm the neuranatomical dissociation, but revealed a far more complex brain organization. An influential PET study by Perani and colleagues employed a lexical decision task with written nouns and verbs, both concrete and abstract (Perani et al., 1999). The comparison between nouns and verbs showed that nouns were not associated with any specific activation. By contrasts, verbs activated a network extending in fronto-temporal areas in the left hemisphere, including Broca's area. This suggested that the greater activations for verbs might actually reflect morphosyntactic processing that might be higher for verbs compared with nouns.

Other experiments on Italian confirmed this idea. Siri and colleagues (Siri et al., 2008) controlled for semantic factors and asked subjects to name the same picture of an event (e.g., a man and a woman dancing) as a verb in the citation form (e.g., ballare, to dance), as an inflected verb (e.g., ballano, they dance), and as an action noun derived from the verb (e.g., ballo, the dance). They did not find specific activations for verbs, but rather an involvement of the left inferior frontal gyrus that increased with higher morphosyntactic engagement. Strongest activation was found for action nouns, intermediate for inflected verbs and weakest for infinitive verb. When studies on the noun-verb distinction tried to limit the influence of confounding factors, such as semantics, temporal lobe differences disappeared, probably due to the heterogeneity of the semantic class used, whereas frontal activations became relevant as a reflection of morphosyntactic processing.

To sum up, thanks to evidence from clinical and neuroimaging studies, the idea that the brain has distinct circuits for nouns and verbs, although appealing, has been radically toned down over the years, leading to the conclusion that the brain is rather sensitive to the greater morphosyntactic engagement of verbs compared with nouns. Italian, with its rich inventory of inflected forms, provided a crucial test bed in this research enterprise. Findings from English, although coming from 
a morphologically poorer language, are consistent with the view of differences related to morphosyntactic characteristics of the two categories (Tyler, Bright, Fletcher, \& Stamatakis, 2004).

\section{Disorders of Language and Cross-Linguistic Differences}

This section deals with studies on language-related disorders following brain damage, showing how patterns of impairment might vary in speakers of Romance languages compared with speakers of other languages or within speakers of different Romance languages. Sub-section 6.1 deals with errors in grammar and considers mostly production tasks, while 6.2 addresses reading impairments.

\subsection{Aphasia and Agrammatism}

The modern study of the language-brain relation starts with the case of a speaker of a Romance language, namely the well-known French case of Louis Victor Leborgne. Paul Broca's writings documented that Monsieur Leborgne, as a consequence of a lesion the size of a hen's egg in the left frontal lobe, produced only the word "tan", repeatedly ("tan, tan"), and occasionally and the more emotional and less well-known outburst "sacré nom de Dieu” (Bastiaanse \& Thompson, 2012; Code, 2013). Notably, what Broca described is not the grammatical disruption that is today associated with Broca's aphasia. Indeed, he focused on articulate language and termed the deficit aphémie. Neither was the lesion in Monsieur Leborgne's brain confined to what we now call Broca's area, but rather it extended largely and affected also fibers of the arcuate fasciculus (Dronkers, Plaisant, Iba-Zizen, \& Cabanis, 2007). On modern accounts, Leborgne's deficit closely resembles severe apraxia of speech (Bastiaanse \& Thompson, 2012) or global aphasia (Code, 2013), where recurring utterances (aka speech automatisms) often occur.

Aphasic speakers might also show agrammatism: Traditionally considered a symptom within the larger syndrome of Broca's aphasia, agrammatism is now more broadly defined on its own, as a language disorder characterized by non-fluent speech with reduced speech rate and grammatically impoverished sentences in which syntactic and morphological devices are limited (Bastiaanse \& 
Thompson, 2012). Research over the years has shown that agrammatism might vary considerably depending on the language in question. For instance, agrammatism appears to be more syntactic in languages with relatively free grammatical word order like Polish, Finnish, and Hebrew. Contrariwise, language with more fixed word order show pattern of agrammatism consisting mainly of dropping out of articles, connective words, auxiliaries, and inflections (Niemi \& Laine, 2012). Focusing on inflection, studies on the Romance family, and especially on Italian, proved key to sharp the theoretical explanation of the patient's errors. For a long time, accounts were indeed based on English, where typical errors in inflected words are like boy for boys or run for runs. Therefore, agrammatism was mainly conceived of as omission of bound morphemes. Studies on Italian questioned this view (Miceli \& Mazzucchi, 1989; Miceli, Silveri, Romani, \& Caramazza, 1989). Errors produced by Italian aphasic speakers are never of the type bambin-corr-for $i$ bambini corrono 'the children run', that is, they never correspond to stem with zero bound morpheme, as this would be an impossible structure in Italian. Rather, Italian patients might produce bambino correre (child M.SG $_{\text {run }}$ INF) selecting incorrect forms of the inflectional paradigm. The outcome of a project collecting narrative production from agrammatic speakers of 14 languages pointed in the same direction (Menn \& Obler, 1989), showing that, for instance, in the nouns of highly-inflecting languages, it is not always the nominative singular (or citation) type that surfaces in agrammatic errors. Hence, what appear to be omissions in languages with poor inflectional morphology are indeed most likely the substitution with an incorrect form of the inflectional paradigm (Niemi \& Laine, 2012). Also, the size of the inflectional paradigm affects the number of inflectional errors in aphasic speakers (Penke, 2008). For instance, substitution errors made up 7.5\% of errors in an elicitation task on Italian article inflection, where 9 forms are available, while they made up $16 \%$ in German, where 12 forms are available (Bates, Friederici, \& Wulfeck, 1987). Consistently with the idea that the characteristics of the language impact the aphasic profile, a study comparing connected speech in monolingual Italian and English speakers diagnosed with the agrammatic variant of primary progressive aphasia showed that the English sample exhibited greater motor speech impairment, 
whereas the Italian sample had greater grammatical impairment, despite comparable disease severity and atrophy changes (Canu et al., 2020).

\subsection{Reading Impairments}

Another domain of crosslinguistic differences is developmental dyslexia, where actually the Romance languages separate quite substantially. Developmental dyslexia is a specific learning disorder characterized by the presence of reading difficulties not accounted for by sensory, neurological, or intellectual deficits. There are differences in the degree to which dyslexia is manifested, as well as in the developmental progress of children learning to read, related to the regularity of the alphabetic system of the specific language (Richlan, 2014; Vellutino, Fletcher, Snowling, \& Scanlon, 2004). In the Romance family, Italian and Spanish are described as transparent (or shallow) orthographies, since they display a relatively consistent mapping between letters and sounds, whereas French has an opaque (or deep) orthography in which the relationships between letters and sounds is less consistent and many exceptions are permitted. Dyslexia is harder to detect in relatively transparent orthographies such as Italian, where implicit phonological processing tests are required (e.g., rapid naming and visual-verbal paired associate learning), whereas diagnosis is clearer in opaque systems such as French, where explicit phonological processing tests (e.g., reading aloud) are sensitive enough. A similar difference is reported between German (transparent) and English (opaque).

Moreover, written languages differ in transparency at the suprasegmental level. Italian, for instance, while being transparent at the segmental level, it is not at the suprasegmental level. A part from the case where stress falls on the last syllable and is obligatorily marked diacritically, for words with more than two syllables stress position is unpredictable and requires access to stored lexical information (see for instance colline 'hills' and polline 'pollen', legato 'bound' and fegato 'liver'). This impacts on the patterns of errors (Folegatti, Pia, Berti, \& Cubelli, 2015). For instance, studies on acquired surface dyslexia have documented that in Italian most errors are stress assignment errors (Chiacchio, Grossi, Stanzione, \& Trojano, 1993; Miceli \& Caramazza, 1993), whereas in Spanish 
most errors involve homophone confusions (e.g., vaso 'glass' /baso/ and bazo 'spleen' /baso/) and lexical decision with pseudohomophones (e.g., camisa 'shirt' /kamisa/ $\rightarrow$ camiza /kamisa/; Ferreres, Cuitiño, \& Olmedo, 2005).

These differences, however, should not obscure the fact that dyslexia has a neurobiological origin and that the brain basis of the disorder is invariant across languages. In a seminal study using PET scan, Paulesu and colleagues tested university students with and without dyslexia from Italy, France, and the UK during a word and pseudo-words reading task (Paulesu et al., 2001). Results evidenced a large cluster of regions in the temporal and occipital lobes of the left hemisphere, which was more activated in non-impaired readers compared with readers with dyslexia, irrespective of orthography. A further study on the same population showed a reduction of gray matter and white matter connectivity (including the left arcuate fasciculus) in dyslexia across the three orthographic systems (Silani et al., 2005), lending further support to the idea that there is some core dysfunction in dyslexia in all writing systems, with additional orthographic-specific aspects (Richlan, 2014).

This section reviewed a number of studies on individuals with brain damage, showing how languagerelated disorders might vary in profile and severity depending on the specific language. In this domain, Romance languages contributed to refine the notion and the mechanisms of agrammatism and to illustrate variations in patterns of reading impairments, due to language-specific segmental and suprasegmental features.

\section{Final Remarks}

There is a large deal of neurolinguistic research conducted on Romance languages, of which this chapter offered a non-exhaustive review. As we underlined throughout the sections, the study of the Romance languages has provided crucial evidence to refine hypotheses on the brain mechanisms mediating language processing in richly inflected systems.

When compared with evidence from other language families, findings from the Romance family pointed out that, although the neural infrastructure for language is invariable, it might be differently 
engaged in different languages. In a similar vein, research in the last decade under the label of "neurotypology" yielded important insights into the brain constraints in the evolution of case-marking systems across languages of diverse genetic affiliation (Bickel, Witzlack-Makarevich, Choudhary, Schlesewsky, \& Bornkessel-Schlesewsky, 2015). This kind of cross-neurolinguistic evidence might may aid to face the granularity mismatch problem raised more than ten years ago and still largely debated (Embick \& Poeppel, 2015; Poeppel \& Embick, 2004), namely the difficulty in linking the fine-grained concepts of linguistic theory and the elemental concepts of neurobiology and cognitive neuroscience due to "immensurability" (Poeppel \& Embick, 2004; p. 14). To date, neurobiological models of language have used coarse-grained distinctions such as production, comprehension, syntax or semantics. Cross-neurolinguistic studies, considering also the Romance family, might help refining such coarse concepts, by pointing to more finely grained linguistic distinctions that are crucial across languages, pruning down others that might lack neural reality. A nice illustration of the potential role of the Romance language in refining the neurolinguistic categories is offered, for instance, by the case of agrammatism described in section 6, where especially studies on Italian contributed to elucidate that agrammatism is not simply omission of morphemes but might involve incorrect substitution from the inflectional paradigm (Miceli et al., 1989; Niemi \& Laine, 2012).

Moreover, interesting insights into language variation through time and space might come from neurolinguistic investigations within the Romance family. With its multitude of languages and dialects and a richly documented diachronic evolution, the Romance family represents - to use Ledgeway \& Maiden's words - a "treasure house" of data for the study of language change and variation which is unparalleled for any other stock of Western languages (Ledgeway \& Maiden, 2016, p. liii). Such treasure is still under-utilized by neurolinguistics scholars. Research has been conducted mainly with Spanish, Italian, and French speakers, while other languages such as Romanian and Portuguese have been so far poorly investigated from the neurolinguistic perspective, not to mention the numerous Romance dialects. First steps in the direction of expanding the scope of neurolinguistic research on the Romance languages are surfacing in the literature of the last few years. Some scholars 
investigated whether the allophonic variants generated by metaphony in an Apulian dialect are processed as phonemes in terms of electrophysiological response to contrasts (Grimaldi, Miglietta, Sigona, \& Calabrese, 2016); others explored if the fading of the neuter gender in a Molise dialect can be captured by means of ERP modulations (Loporcaro, 2018). There is also evidence of how aphasic insults can affect the linguistic skills of speakers of Friulan, with agrammatism displayed especially in the system of obligatory pronouns characteristic of that dialect (Fabbro \& Frau, 2001). We think that, after decades of advances in the knowledge of the main language systems, the neurolinguistics community should open to a more mature investigation of the Romance patrimony, overcoming disciplinary boundaries, taking into account typological and diachronic considerations, and truly embracing the interdisciplinary nature of the study of language.

\section{Authors' contribution}

Although the authors conceived and revised the article jointly, VB is mainly responsible for sections 1, 3, 5, 6 and 7, whereas PC is mainly responsible for sections 2 and 4 . 


\section{References}

Amunts, K., Lenzen, M., Friederici, A. D., Schleicher, A., Morosan, P., Palomero-Gallagher, N., \& Zilles, K. (2010). Broca's region: Novel organizational principles and Multiple Receptor Mapping. PLoS Biology, 8(9). https://doi.org/10.1371/journal.pbio.1000489

Angrilli, A., Penolazzi, B., Vespignani, F., De Vincenzi, M., Job, R., Ciccarelli, L., ... Stegagno, L. (2002). Cortical brain responses to semantic incongruity and syntactic violation in Italian language: an event-related potential study. Neuroscience Letters, 322(1), 5-8.

Bambini, V. (2012). Neurolinguistics. In J.-O. Östman \& J. Verschueren (Eds.), Handbook of Pragmatics (pp. 1-34). https://doi.org/10.1075/hop.16.neu1

Bambini, V., Gentili, C., Ricciardi, E., Bertinetto, P. M., \& Pietrini, P. (2011). Decomposing metaphor processing at the cognitive and neural level through functional magnetic resonance imaging. Brain Research Bulletin, 86(3-4). https://doi.org/10.1016/j.brainresbull.2011.07.015

Barber, H., \& Carreiras, M. (2005). Grammatical gender and number agreement in Spanish: An ERP comparison. Journal of Cognitive Neuroscience, 17(1), 137-153. https://doi.org/10.1162/0898929052880101

Basser, P. J., Mattiello, J., \& LeBihan, D. (1994). MR diffusion tensor spectroscopy and imaging. Biophysical Journal, 66(1), 259-267. https://doi.org/10.1016/S0006-3495(94)80775-1

Bastiaanse, R., \& Thompson, C. K. (2012). Introduction to agrammatism. In R. Bastiaanse \& C. K. Thompson (Eds.), Perspective on Agrammatism (pp. 1-16). New York, NY: Psychology Press.

Bates, E., Friederici, A., \& Wulfeck, B. (1987). Comprehension in aphasia: A cross-linguistic study. Brain and Language, 32(1), 19-67.

Benetello, A., Finocchiaro, C., Capasso, R., Capitani, E., Laiacona, M., Magon, S., \& Miceli, G. (2016). The dissociability of lexical retrieval and morphosyntactic processes for nouns and verbs: A functional and anatomoclinical study. Brain and Language, 159, 11-22. https://doi.org/10.1016/j.bandl.2016.05.005 
Bickel, B., Witzlack-Makarevich, A., Choudhary, K. K., Schlesewsky, M., \& BornkesselSchlesewsky, I. (2015). The neurophysiology of language processing shapes the evolution of grammar: Evidence from case marking. PLOS ONE, 10(8), e0132819. https://doi.org/10.1371/journal.pone.0132819

Binder, J. R., Desai, R. H., Graves, W. W., \& Conant, L. L. (2009). Where is the semantic system? A critical review and meta-analysis of 120 functional neuroimaging studies. Cerebral Cortex, 19(12), 2767-2796. https://doi.org/10.1093/cercor/bhp055

Bossong, G. (2016). Classification. In A. Ledgeway \& M. Maiden (Eds.), The Oxford Guide to the Romance Languages (pp. 63-72). Oxford: Oxford University Press.

Caffarra, S., \& Barber, H. A. (2015). Does the ending matter? The role of gender-to-ending consistency in sentence reading. Brain Research, 1605(1), 83-92. https://doi.org/10.1016/j.brainres.2015.02.018

Caffarra, S., Janssen, N., \& Barber, H. A. (2014). Two sides of gender: ERP evidence for the presence of two routes during gender agreement processing. Neuropsychologia, 63, 124-134. https://doi.org/10.1016/j.neuropsychologia.2014.08.016

Caffarra, S., Mendoza, M., \& Davidson, D. (2019). Is the LAN effect in morphosyntactic processing an ERP artifact? Brain and Language, 191, 9-16. https://doi.org/10.1016/j.bandl.2019.01.003

Caffarra, S., Siyanova-Chanturia, A., Pesciarelli, F., Vespignani, F., \& Cacciari, C. (2015). Is the noun ending a cue to grammatical gender processing? An ERP study on sentences in Italian. Psychophysiology, 52(8), 1019-1030. https://doi.org/10.1111/psyp.12429

Callahan, S. M. (2008). Processing anaphoric constructions: Insights from electrophysiological studies. Journal of Neurolinguistics, 21(3), 231-266. https://doi.org/10.1016/J.JNEUROLING.2007.10.002

Canu, E., Agosta, F., Battistella, G., Spinelli, E. G., DeLeon, J., Welch, A. E., ... Gorno-Tempini, M. L. (2020). Speech production differences in English and Italian speakers with nonfluent 
variant PPA. Neurology, 94(10), e1062-e1072.

https://doi.org/10.1212/WNL.0000000000008879

Cappa, S. F. (2012). Imaging semantics and syntax. NeuroImage, 61(2), 427-431.

https://doi.org/10.1016/j.neuroimage.2011.10.006

Cappa, S. F., Binetti, G., Pezzini, A., Padovani, A., Rozzini, L., \& Trabucchi, M. (1998). Object and action naming in Alzheimer's disease and frontotemporal dementia. Neurology, 50(2), 351-355. https://doi.org/10.1212/WNL.50.2.351

Carreiras, M., Carr, L., Barber, H. A., \& Hernandez, A. (2010). Where syntax meets math: Right intraparietal sulcus activation in response to grammatical number agreement violations. NeuroImage, 49(2), 1741-1749. https://doi.org/10.1016/j.neuroimage.2009.09.058

Carreiras, M., Quiñones, I., Mancini, S., Hernández-Cabrera, J. A., \& Barber, H. (2015). Verbal and nominal agreement: An fMRI study. NeuroImage, 120, 88-103.

https://doi.org/10.1016/j.neuroimage.2015.06.075

Catani, M., \& Bambini, V. (2014). A model for Social Communication And Language Evolution and Development (SCALED). Current Opinion in Neurobiology, 28, 165-171. https://doi.org/10.1016/j.conb.2014.07.018

Catani, M., \& Mesulam, M. M. (2008). The arcuate fasciculus and the disconnection theme in language and aphasia: History and current state. Cortex, 44(8), 953-961. https://doi.org/10.1016/j.cortex.2008.04.002

Chiacchio, L., Grossi, D., Stanzione, M., \& Trojano, L. (1993). Slowly Progressive Aphasia Associated with Surface Dyslexia. Cortex, 29(1), 145-152. https://doi.org/10.1016/S00109452(13)80219-5

Code, C. (2013). Did Leborgne have one or two speech automatisms? Journal of the History of the Neurosciences, 22(3), 319-320. https://doi.org/10.1080/0964704X.2013.776296

Corbett, G. G. (2006). Agreement. Cambridge: Cambridge University Press.

Cotelli, M., Borroni, B., Manenti, R., Alberici, A., Calabria, M., Agosti, C., ... Cappa, S. F. (2006). 
Action and object naming in frontotemporal dementia, progressive supranuclear palsy, and corticobasal degeneration. Neuropsychology, 20(5), 558-565. https://doi.org/10.1037/08944105.20.5.558

Crepaldi, D., Berlingeri, M., Paulesu, E., \& Luzzatti, C. (2011). A place for nouns and a place for verbs? A critical review of neurocognitive data on grammatical-class effects. Brain and Language, 116(1), 33-49. https://doi.org/10.1016/j.bandl.2010.09.005

Dal Maso, S. (2015). Una descrizione del linguaggio afasico ante litteram. Studi Italiani Di Linguistica Teorica e Applicata (SILTA), XLIV(3), 402-417.

Damasio, A. R., \& Tranel, D. (1993). Nouns and verbs are retrieved with differently distributed neural systems. Proceedings of the National Academy of Sciences of the United States of America, 90(11), 4957-4960. https://doi.org/10.1073/pnas.90.11.4957

Daniele, A., Giustolisi, L., Silveri, M. C., Colosimo, C., \& Gainotti, G. (1994). Evidence for a possible neuroanatomical basis for lexical processing of nouns and verbs. Neuropsychologia, 32(11), 1325-1341. https://doi.org/10.1016/0028-3932(94)00066-2

De Vincenzi, M., Job, R., Di Matteo, R., Angrilli, A., Penolazzi, B., Ciccarelli, L., \& Vespignani, F. (2003). Differences in the perception and time course of syntactic and semantic violations. Brain and Language, 85(2), 280-296.

Denes, G. (2011). Talking heads : the neuroscience of language. New York, NY: Psychology Press. Domaneschi, F., Canal, P., Masia, V., Lombardi Vallauri, E., \& Bambini, V. (2018). N400 and P600 modulation in presupposition accommodation: The effect of different trigger types. Journal of Neurolinguistics, 45. https://doi.org/10.1016/j.jneuroling.2017.08.002

Dronkers, N. F., Plaisant, O., Iba-Zizen, M. T., \& Cabanis, E. A. (2007). Paul Broca’s historic cases: High resolution MR imaging of the brains of Leborgne and Lelong. Brain, 130(5), 1432-1441. https://doi.org/10.1093/brain/awm042

Embick, D., Marantz, A., Miyashita, Y., O’Neil, W., \& Sakai, K. L. (2000). A syntactic specialization for Broca's area. Proceedings of the National Academy of Sciences of the United 
States of America, 97(11), 6150-6154. https://doi.org/10.1073/pnas.100098897

Embick, D., \& Poeppel, D. (2015). Towards a computational(ist) neurobiology of language: correlational, integrated and explanatory neurolinguistics. Language, Cognition and Neuroscience, 30(4), 357-366. https://doi.org/10.1080/23273798.2014.980750

Fabbro, F., \& Frau, G. (2001). Manifestations of aphasia in Friulian. Journal of Neurolinguistics, 14(2-4), 255-279. https://doi.org/10.1016/S0911-6044(01)00017-3

Ferreres, A. R., Cuitiño, M. M., \& Olmedo, A. (2005). Acquired surface alexia in Spanish: a case report. Behavioural Neurology, 16(2-3), 71-84. https://doi.org/10.1155/2005/473407

Folegatti, A., Pia, L., Berti, A., \& Cubelli, R. (2015). Stress Assignment Errors in Surface Dyslexia: Evidence from Two Italian Patients with a Selective Deficit of the Orthographic Input Lexicon. Behavioural Neurology, 2015, 1-8. https://doi.org/10.1155/2015/769013

Frenck-Mestre, C., Osterhout, L., McLaughlin, J., \& Foucart, A. (2008). The effect of phonological realization of inflectional morphology on verbal agreement in French: Evidence from ERPs. Acta Psychologica, 128(3), 528-536. https://doi.org/10.1016/j.actpsy.2007.12.007

Friederici, A. D., \& Gierhan, S. M. E. (2013). The language network. Current Opinion in Neurobiology, 23(2), 250-254. https://doi.org/10.1016/j.conb.2012.10.002

Gazzaniga, M. S., Ivry, R. B., \& Mangun, G. R. (2014). Cognitive Neuroscience (4th ed.). New York: Norton.

German, E. S., Herschensohn, J., \& Frenck-Mestre, C. (2015). Pronoun processing in anglophone late L2 learners of French: Behavioral and ERP evidence. Journal of Neurolinguistics, 34, 1540. https://doi.org/10.1016/J.JNEUROLING.2014.12.001

Goodale, M. A., \& Milner, A. D. (1992). Separate visual pathways for perception and action. Trends in Neurosciences, 15(1), 20-25.

Grimaldi, M., Miglietta, S., Sigona, F., \& Calabrese, A. (2016). On integrating different methodologies in phonological research: acoustic, articulatory, behavioral and neurophysiological evidence in the study of a metaphony system. In F. Torres-Tamarit, K. 
Linke, \& M. van Oostendorp (Eds.), Approaches to Metaphony in the Languages of Italy (pp. 195-219). Berlin: De Gruyter.

Hagoort, P., \& Levinson, S. C. (2014). Neuropragmatics. In M. S. Gazzaniga (Ed.), The Cognitive Neurosciences (5th ed., pp. 667-674). Cambridge, Mass: MIT Press.

Hansen, P., Kringelbach, M., \& Salmelin, R. (Eds.). (2010). MEG: An Introduction to Methods. New York: Oxford University Press.

Hernandez, A. E., Kotz, S. A., Hofmann, J., Valentin, V. V, Dapretto, M., \& Bookheimer, S. Y. (2004). The neural correlates of grammatical gender decisions in Spanish. Neuroreport, 15(5), 863-866. https://doi.org/10.1097/00001756-200404090-00026

Hickok, G. (2009). The functional neuroanatomy of language. Physics of Life Reviews, 6(3), 121143. https://doi.org/10.1016/j.plrev.2009.06.001

Hickok, G. (2012). The cortical organization of speech processing: Feedback control and predictive coding the context of a dual-stream model. Journal of Communication Disorders, 45(6), 393402. https://doi.org/10.1016/j.jcomdis.2012.06.004

Hickok, G., \& Poeppel, D. (2007). The cortical organization of speech processing. Nature Reviews. Neuroscience, 8(5), 393-402.

Huettel, S. A., Song, A. W., \& McCharthy, G. (2008). Functional Magnetic Resonance Imaging (2nd ed.). Sunderland, MA: Sinauer Associates Inc.

Indefrey, P., Hagoort, P., Herzog, H., Seitz, R. J., \& Brown, C. M. (2001). Syntactic processing in left prefrontal cortex is independent of lexical meaning. NeuroImage, 14(3), 546-555. https://doi.org/10.1006/nimg.2001.0867

Kaan, E. (2009). Fundamental syntactic phenomena and their putative relation to the brain. In D. Bickerton \& E. Szathmáry (Eds.), Biological Foundations and Origin of Syntax (pp. 117-133). https://doi.org/10.7551/mitpress/9780262013567.003.0006

Kemmerer, D. (2014). Word classes in the brain: Implications of linguistic typology for cognitive neuroscience. Cortex, 58, 27-51. https://doi.org/10.1016/j.cortex.2014.05.004 
Knecht, S., Dräger, B., Deppe, M., Bobe, L., Lohmann, H., Flöel, A., ... Henningsen, H. (2000). Handedness and hemispheric language dominance in healthy humans. Brain, 123(12), 2512 2518. https://doi.org/10.1093/brain/123.12.2512

Kutas, M., \& Federmeier, K. D. (2011). Thirty years and counting: Finding meaning in the N400 component of the event-related brain potential (ERP). Annual Review of Psychology, 62, 621647. https://doi.org/10.1146/annurev.psych.093008.131123

Lambon Ralph, M. A., Jefferies, E., Patterson, K., \& Rogers, T. T. (2016). The neural and computational bases of semantic cognition. Nature Reviews Neuroscience, 1-14. https://doi.org/10.1038/nrn.2016.150

Ledgeway, A., \& Maiden, M. (2016). Introduction. In The Oxford Guide to the Romance Languages (pp. liii-liv). Oxford: Oxford University Press.

Logothetis, N. K. (2008). What we can do and what we cannot do with fMRI. Nature, 453(7197), 869-878. https://doi.org/10.1038/nature06976

Loporcaro, M. (2018). Gender from Latin to Romance: History, Geography, Typology. Oxford: Oxford University Press.

Luck, S. J., \& Kappenman, E. S. (2012). The Oxford Handbook of Event-Related Potential Components. Oxford: Oxford University Press.

Mancini, S., Molinaro, N., Rizzi, L., \& Carreiras, M. (2011). A person is not a number: Discourse involvement in subject-verb agreement computation. Brain Research, 1410, 64-76. https://doi.org/10.1016/j.brainres.2011.06.055

Mancini, S., Quiñones, I., Molinaro, N., Hernandez-Cabrera, J. A., \& Carreiras, M. (2017). Disentangling meaning in the brain: Left temporal involvement in agreement processing. Cortex, 86, 140-155. https://doi.org/10.1016/j.cortex.2016.11.008

Masia, V., Canal, P., Ricci, I., Lombardi Vallauri, E., \& Bambini, V. (2017). Presupposition of new information as a pragmatic garden path: Evidence from Event-Related Brain Potentials. Journal of Neurolinguistics, 42. https://doi.org/10.1016/j.jneuroling.2016.11.005 
Mätzig, S., Druks, J., Masterson, J., \& Vigliocco, G. (2009). Noun and verb differences in picture naming: Past studies and new evidence. Cortex, 45(6), 738-758. https://doi.org/10.1016/j.cortex.2008.10.003

McCarthy, R. A., \& Warrington, E. K. (1990). Cognitive Neuropsychology : A Clinical Introduction. San Diego: Academic Press.

Menn, L., \& Obler, L. K. (Eds.). (1989). Agrammatic Aphasia. A Cross-Language Narrative Sourcebook. https://doi.org/10.1075/z.39

Mesgarani, N., Cheung, C., Johnson, K., \& Chang, E. F. (2014). Phonetic feature encoding in human superior temporal gyrus. Science (New York, N.Y.), 343(6174), 1006-1010. https://doi.org/10.1126/science.1245994

Miceli, G., \& Caramazza, A. (1993). The assignment of word stress in oral reading: Evidence from a case of acquired dyslexia. Cognitive Neuropsychology, 10(3), 273-295. https://doi.org/10.1080/02643299308253465

Miceli, G., \& Mazzucchi, A. (1989). Agrammatism in Italian: Two case studies. In L. Menn \& L. K. Obler (Eds.), Agrammatic Aphasia. A Cross-Language Narrative Sourcebook (pp. 717816). Amsterdam: John Benjamins.

Miceli, G., Silveri, M. C., Romani, C., \& Caramazza, A. (1989). Variation in the pattern of omissions and substitutions of grammatical morphemes in the spontaneous speech of so-called agrammatic patients. Brain and Language, 36(3), 447-492. https://doi.org/10.1016/0093934X(89)90079-5

Miceli, G., Turriziani, P., Caltagirone, C., Capasso, R., Tomaiuolo, F., \& Caramazza, A. (2002). The Neural Correlates of Grammatical Gender: An fMRI Investigation. Journal of Cognitive Neuroscience, 14(4), 618-628. https://doi.org/10.1162/08989290260045855

Molinaro, N., Barber, H. A., \& Carreiras, M. (2011). Grammatical agreement processing in reading: ERP findings and future directions. Cortex, 47(8), 908-930. https://doi.org/10.1016/j.cortex.2011.02.019 
Molinaro, N., Barber, H. A., Pérez, A., Parkkonen, L., \& Carreiras, M. (2013). Left fronto-temporal dynamics during agreement processing: Evidence for feature-specific computations. NeuroImage, 78, 339-352. https://doi.org/10.1016/j.neuroimage.2013.04.025

Molinaro, N., Vespignani, F., \& Job, R. (2008). A deeper reanalysis of a superficial feature: An ERP study on agreement violations. Brain Research, 1228, 161-176. https://doi.org/10.1016/j.brainres.2008.06.064

Molinaro, N., Vespignani, F., Zamparelli, R., \& Job, R. (2011). Why brother and sister are not just siblings: Repair processes in agreement computation. Journal of Memory and Language, 64(3), 211-232. https://doi.org/10.1016/J.JML.2010.12.002

Moro, A., Tettamanti, M., Perani, D., Donati, C., Cappa, S. F., \& Fazio, F. (2001). Syntax and the brain: Disentangling grammar by selective anomalies. NeuroImage, 13(1), 110-118. https://doi.org/10.1006/nimg.2000.0668

Niemi, J., \& Laine, M. (2012). Lexical, inflectional, and clitic morphology: Evidence from an agrammatic aphasic individual. In R. Bastiaanse \& C. K. Thompson (Eds.), Perspectives on Agrammatism (pp. 106-119). New York, NY: Psychology Press.

Obler, L. K., \& Gjerlow, K. (1999). Language and the Brain. Cambridge University Press.

Padovani, R., Calandra-Buonaura, G., Cacciari, C., Benuzzi, F., \& Nichelli, P. (2005). Grammatical gender in the brain: Evidence from an fMRI study on Italian. Brain Research Bulletin, 65(4), 301-308. https://doi.org/10.1016/j.brainresbull.2004.11.025

Pallier, C., Devauchelle, A.-D., \& Dehaene, S. (2011). Cortical representation of the constituent structure of sentences. Proceedings of the National Academy of Sciences of the United States of America, 108(6), 2522-2527. https://doi.org/10.1073/pnas.1018711108

Patterson, K., Nestor, P. J., \& Rogers, T. T. (2007). Where do you know what you know? The representation of semantic knowledge in the human brain. Nature Reviews Neuroscience, 8(12), 976-987. https://doi.org/10.1038/nrn2277

Paulesu, E., Démonet, J. F., Fazio, F., McCrory, E., Chanoine, V., Brunswick, N., ... Frith, U. 
(2001). Dyslexia: Cultural diversity and biological unity. Science, 291(5511), 2165-2167. https://doi.org/10.1126/science.1057179

Penke, M. (2008). Morphology and language disorder. In M. J. Ball, M. R. Perkins, N. Müller, \& S. Howard (Eds.), Clinical Linguistics (pp. 212-227). Malden, MA: Blackwell.

Perani, D., Cappa, S. F., Schnur, T., Tettamanti, M., Collina, S., Rosa, M. M., \& Fazio, F. (1999). The neural correlates of verb and noun processing. A PET study. Brain : A Journal of Neurology, 122 ( Pt 12), 2337-2344.

Poeppel, D., \& Embick, D. (2004). Defining the relation between linguistics and neuroscience. Linguistics, (1), 1-16. https://doi.org/citeulike-article-id:6138571

Richlan, F. (2014). Functional neuroanatomy of developmental dyslexia: The role of orthographic depth. Frontiers in Human Neuroscience, 8, 347. https://doi.org/10.3389/fnhum.2014.00347

Ritaccio, A., Matsumoto, R., Morrell, M., Kamada, K., Koubeissi, M., Poeppel, D., ... Schalk, G. (2015). Proceedings of the Seventh International Workshop on Advances in Electrocorticography. Epilepsy and Behavior, 51, 312-320. https://doi.org/10.1016/j.yebeh.2015.08.002

Rossi, E., Kroll, J. F., \& Dussias, P. E. (2014). Clitic pronouns reveal the time course of processing gender and number in a second language. Neuropsychologia, 62, 11-25. https://doi.org/10.1016/j.neuropsychologia.2014.07.002

Sejnowski, T. J., Churchland, P. S., \& Movshon, J. A. (2014). Putting big data to good use in neuroscience. Nature Neuroscience, 17(11), 1440-1441. https://doi.org/10.1038/nn.3839

Silani, G., Frith, U., Demonet, J.-F., Fazio, F., Perani, D., Price, C., ... Paulesu, E. (2005). Brain abnormalities underlying altered activation in dyslexia: A voxel based morphometry study. Brain, 128(10), 2453-2461. https://doi.org/10.1093/brain/awh579

Siri, S., Tettamanti, M., Cappa, S. F., Rosa, P. D., Saccuman, C., Scifo, P., \& Vigliocco, G. (2008). The neural substrate of naming events: Effects of processing demands but not of grammatical class. Cerebral Cortex, 18(1), 171-177. https://doi.org/10.1093/cercor/bhm043 
Small, S. L., Hickok, G., Nusbaum, H. C., Blumstein, S., Branch Coslett, H., Dell, G., ... Wise, R. J. S. (2011). The neurobiology of language: Two years later. Brain and Language, 116(3), 103-104. https://doi.org/10.1016/j.band1.2011.02.004

Spotorno, N., Koun, E., Prado, J., Van Der Henst, J.-B., \& Noveck, I. A. (2012). Neural evidence that utterance-processing entails mentalizing: the case of irony. NeuroImage, 63(1), 25-39. https://doi.org/10.1016/j.neuroimage.2012.06.046

Tyler, L. K., Bright, P., Fletcher, P., \& Stamatakis, E. A. (2004). Neural processing of nouns and verbs: the role of inflectional morphology. Neuropsychologia, 42, 512-523.

Tyler, L. K., \& Marslen-Wilson, W. (2008). Fronto-temporal brain systems supporting spoken language comprehension. Philosophical Transactions of the Royal Society of London. Series B, Biological Sciences, 363(1493), 1037-1054. https://doi.org/10.1098/rstb.2007.2158

Ullman, M. T. (2001). A neurocognitive perspective on language: The declarative/procedural model. Nature Reviews Neuroscience, 2, 717-721.

Van Berkum, J. J. A., Koornneef, A. W., Otten, M., \& Nieuwland, M. S. (2007). Establishing reference in language comprehension: An electrophysiological perspective. Brain Research, 1146, 158-171. https://doi.org/10.1016/j.brainres.2006.06.091

Vellutino, F. R., Fletcher, J. M., Snowling, M. J., \& Scanlon, D. M. (2004). Specific reading disability (dyslexia): What have we learned in the past four decades ? Journal of Child Psychology and Psychiatry, 45, 2-40. https://doi.org/10.1046/j.0021-9630.2003.00305.x

Vigliocco, G., Vinson, D. P., Druks, J., Barber, H., \& Cappa, S. F. (2011). Nouns and verbs in the brain: A review of behavioural, electrophysiological, neuropsychological and imaging studies. Neuroscience and Biobehavioral Reviews, 35(3), 407-426.

https://doi.org/10.1016/j.neubiorev.2010.04.007

Zacks, J. M., \& Ferstl, E. C. (2016). Discourse comprehension. In G. Hickock \& S. L. Small (Eds.), Neurobiology of Language (pp. 661-673). https://doi.org/10.1016/B978-0-12-4077942.00053-5 


\section{Notes}

${ }^{\mathrm{i}}$ For graphical illustrations of the different techniques and apparatuses, see Gazzaniga, Ivry, \& Mangun (2014), and specifically figure 3.24 for EEG/ERP, figure 3.27 for MEG, figure 3.28 for ECoG, and figure 3.29 for PET.

ii Interestingly, also other types of local dependency violations not considered here, such as phrase structure violations (i.e., word order violations), seem to elicit a LAN-P600 pattern. For a review on different syntactic violations, see Kaan (2009). 